\title{
Evaluation of Differential Protection in a Main Power Transformer: A Case Study in PT Pertamina Geothermal Energy Area of Kamojang
}

\author{
Gady Altama*1, Muhamad Yusvin Mustar ${ }^{1}$, Ramadoni Syahputra ${ }^{1}$, Teguh Iman Prasetyo ${ }^{2}$ \\ ${ }^{1}$ Department of Electrical Engineering, Universitas Muhammadiyah Yogyakarta \\ Jl. Lingkar Selatan, Tamantirto, Kasihan, Yogyakarta, Indonesia \\ ${ }^{2}$ Production on the Job Trainer and Competence Assessor, Petroleum Development Oman \\ Muscat, Sultanate of Oman \\ *Corresponding author, e-mail: gadyaltama56@gmail.com
}

\begin{abstract}
The electric power system consists of various components, ranging from the components of generation, transmission, and distribution. The systems are quite expensive, so that excellent, reliable, and economic protection is needed to avoid internal and external faults. The faults can trigger damage to components, especially on the main transformers in the Power Plant Geothermal Unit 4 of the Kamojang area managed by PT Pertamina Geothermal Energy. Disturbances that occur in the main transformers of various types so that the primary protection needed in the transformer is a differential relay to protect to avoid interference that occurs. This study discusses the comparison of theoretical differential relay calculation calculations with actual differential relay setting data in the Kamojang Unit 4 Geothermal Power Plant and simulates with ETAP 12.6 software. The problem that occurs in the main transformer of the Geothermal Power Unit Unit 4 Kamojang area is the difference in the slope 1 of the actual setting data with a mathematical calculation that is the actual setting data of $40 \%$ and the numerical calculation data worth $8.5 \%$. Please note that the minimum slope one limit is 5\%. PT Pertamina Geothermal Energy made slope one changes, so that differential relays are not too sensitive to the interference current that occurs within the protection zone of differential relays.
\end{abstract}

Keywords: Main Transformer, Differential Relay, ETAP Software

\section{Introduction}

The need for electrical energy is a primary need for the people of Indonesia. This fact requires PLN to increase the supply of electricity. For this reason, the quality and continuity of the distribution of electricity become very important, especially in the distribution of electricity in operating electricity must be reliable, uninterrupted [1]. They can continuously deliver electricity to PLN customers. An alternative to the use of electricity is that renewable energy has been developed. Renewable energy is geothermal. Geothermal is more accurately called sustainable energy, because if it is explored continuously and not appropriately managed, then geothermal energy will also be depleted. Its development in Indonesia is not largescale due to the presence of geothermal resources in protected forest areas, substantial initial investment costs, and low electricity purchase tariffs by PLN, making the initial capital investment return very long. One of the developments of geothermal energy is in Kamojang, which is managed by PT Pertamina Geothermal Energy [2].

A power transformer is the central and most important part of the distribution and distribution of electrical energy. Along with the increasing demand for electrical energy, the need for transformers by itself increases following the increasing amount of electric power generated. Because of the above background, the writer identifies, analyzes, and 
evaluates the protection system on the main transformer that is in Unit 4 Geothermal Power Plant at PT Pertamina Geothermal Energy Kamojang area. The author does this by comparing the calculation of differential relay settings based on a theory with differential relay settings on the main transformer at PLTP Kamojang unit 4 to determine the reliability of the protection system and simulate differential relay on the main transformer with ETAP 12.6 software.

\section{Literature Study \\ II.1 Power Transformer}

A power transformer is a static electrical device that is used to move power from one circuit to another by changing the voltage without changing the frequency [3]. A transformer can also be interpreted as a device that converts alternating current voltage from one level to another through magnetic coupling and is based on the principles of induction-electromagnet. The transformer consists of a core, made of layered iron and two coils, the primary coil and the secondary coil. Transformers are widely used, both in the electric and electronic fields [4]. The use of transformers in electric power systems allows the selection of appropriate and economical voltage for each purpose, for example, the need for high voltage in the transmission of electric power over long distances [5].

In its purest form, the transformer consists of two coils and one mutual inductance. The primary coil is the one receiving power, and the secondary coil is connected to the load. The two coils are wrapped around a core consisting of laminated magnetic material. The physical foundation of the transformer is mutual inductance between the two circuits connected by a shared magnetic flux that passes through the path of low reluctance. Both coils have high mutual inductance [6]. If the primary coil is connected to the voltage, an alternating current will flow in the coil. Because the coil has a core, the current causes a magnetic flux that also changes at its core. Due to the changing magnets in the primary coil induction, GGL will arise. Figure 1 shows the typical power transformer in an outdoor substation.

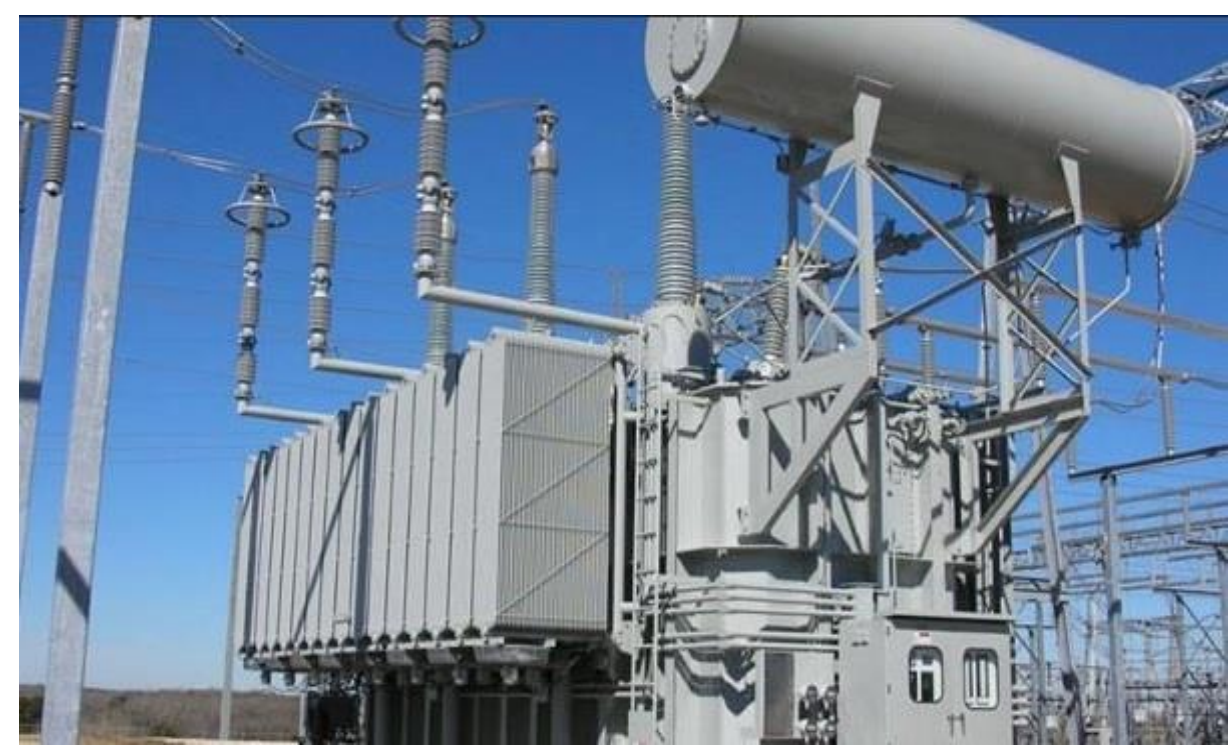

Fig. 1. Typical power transformer in an outdoor substation

Disturbances that affect transformer damage are not only due to interference inside the transformer or inside the transformer safety area, but also outside the safety area [7].

1. Interference outside the safety area

Disturbances outside the security area of this power transformer often occur and can be an overload, short circuit single phase to the ground, or interphase interruption. This disturbance in this area has an influence on this transformer, so the transformer must be released or separated if the disturbance occurs after a specific time to provide an opportunity to safeguard the disturbed area from working. Continuous overload conditions can be detected by a thermal relay or thermometer that provides a signal so that it can regulate or manipulate the network so that the load is reduced, but if necessary, it is decided to supply. For fault conditions outside the area such as short circuit interference on the rail or short circuit interference 
in the outlet, the overcurrent relays with slowing time or fuses are used as a safety. Good coordination for the safety of this backup transformer needs to be created for the next relevant area's safety. The main safety of this transformer is made in such a way that it is not allowed to work against the interference mentioned above [8].

2. Disturbances in the safety area

The primary safety of the power transformer is shown as a safety in the safety area. The internal disturbances are severe, and there is always a risk of fire, internal disturbances can be classified into two groups, namely:

Group (a)

- Electrical interruptions will immediately cause severe damage but can generally be detected by an unbalanced current or voltage, including:

- Single-phase or inter-phase interference on the side of the high voltage or low voltage on the outer terminal.

- Single-phase or interphase interference on high voltage or low voltage side windings. Short circuit between windings on the side of high or low voltage.

- Land disturbance in tertiary windings, or short circuit between windings in tertiary windings.

\section{Group (b)}

What is called a disturbance is a disturbance that starts a small or insignificant disturbance, but will slowly cause damage. This disturbance cannot detect a voltage or increase the amount of current at the end of the coil. Included in this convolution disorder are:

- Electrical connections of poor conductors and core disturbances such as breakage of the core insulation layer and less tight bolts or clamp rings, which will cause arcs to be limited to oil.

- Cooling system disruption, which will cause overheating even though the load has not yet reached the nominal. In connection with point 2 is the possibility of lack of oil or blockage of oil flow causing local heating of the windings.

- Disturbances from voltage regulators and poor load sharing between transformers that work in parallel, which will cause overheating due to circulating currents.

In general, for group interference (a) the disturbed equipment must be separated as soon as possible after the fault occurs, not only to limit the damage of the power transformer but also to limit the amount of time the system voltage drops. If the voltage drops too long, it can cause a loss of synchronization between machines. If this happens, a large overcurrent will occur due to the synchronous loss of the generating unit so that there will be a relay that is working incorrectly, causing a continuous disturbance. Disturbances in the group (b) are not severe during incipient disorders but can become severe disorders depending on time, so they must be eliminated as soon as possible. If safety for the group (a) is not able to secure the disturbance in the group (b), then for security for the group (b), it is not necessary to detect interference in the terminal and to eliminate unnecessary disturbance as quickly as interference in the group (a). This is the underlying philosophy of securing power transformers, and this means that group safety (a).

The current transformer is used to measure the load current of a circuit. By using a current transformer, a large load current can be measured only by using a measuring instrument (amperemeter) that is not too large. Current transformer circuit was shown in Figure 2.

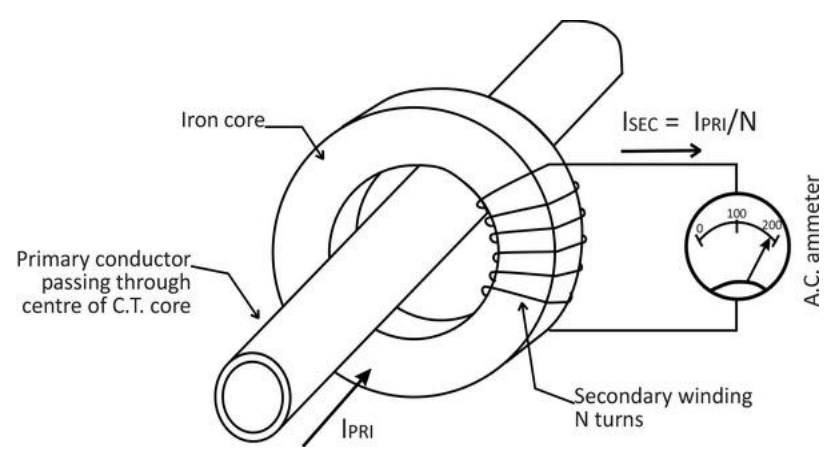

Fig. 2. Current transformer circuit

By knowing the $\mathrm{N}_{1} / \mathrm{N}_{2}$ transformation ratio and the reading of the ammeter $\left(I_{2}\right)$, the load current $I_{1}$ can be calculated. If the transformer is considered ideal, then the load current:

$$
\mathrm{I}_{1}=\mathrm{N}_{2} / \mathrm{N}_{1} \times \mathrm{I}_{2}
$$

To keep the flux unchanged, it should be noted that the secondary circuit is always closed. In an open secondary circuit, the $\mathrm{N}_{2} \mathrm{I}_{2} \mathrm{mmf}$ will be zero (because of $h=0$ ) while the $\mathrm{N}_{1} / \mathrm{I}_{1} \mathrm{mmf}$ remains so that the normal flux will be disrupted.

The voltage transformer is used to measure voltage. By knowing $\mathrm{N}_{1}$ and $\mathrm{N}_{2}$, reading voltage $\mathrm{V}_{2}$ and assuming an ideal transformer, voltage $V_{1}$ is:

$$
\mathrm{V}_{1}=\mathrm{N}_{1} / \mathrm{N}_{2} \mathrm{~V}_{2}
$$


Secondary circuit grounding is required to prevent; there is a large potential difference between the primary and secondary coils (between points $a$ and $b$ ) when the primary coil insulation is broken. Figure 3 shows the typical of voltage transformer in an outdoor substation.

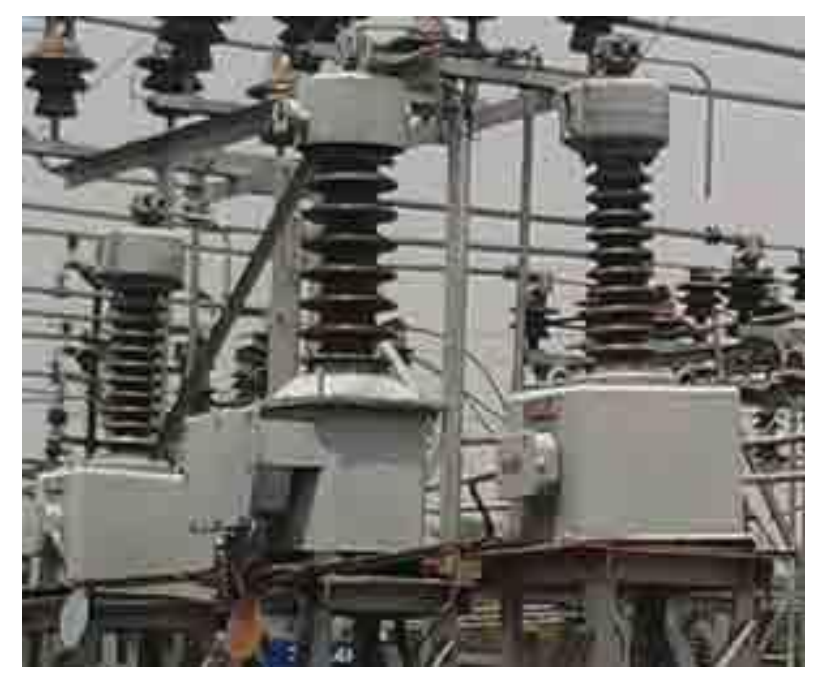

Fig. 3. Typical of voltage transformer in an outdoor substation

A circuit breaker (CB) is needed to cut off working currents or short-circuit currents. The power cut can be operated, i.e., closed or opened in place or remotely using a protection system [9]. Thus a CB can automatically open a circuit when, for example, a line current, line voltage, or system frequency exceeds certain limits. The most important types of $\mathrm{CB}$ are:
a. Oil circuit breakers
b. Airblast circuit breakers
c. SF6 power breakers
d. Vacuum circuit breakers

The nameplate of a CB generally indicates:

a. The maximum constant current used

b. Maximum interrupt current size

c. Maximum channel voltage

d. The interruption time stated in the cycle

The interruption time can range up to 3 or 8 cycles on a $50 \mathrm{~Hz}$ system. To interrupt large electric currents in such a short time, it is necessary to regulate the rapid de-ionization of the arc, along with rapid cooling. High-speed interruptions limit the damage that can occur in transmission installations and other equipment, as well as maintain system stability in the event of an emergency. A power breaker will work because, for example, driven by a safety device in the form of overcurrent relays. The ability of a power switch is expressed in a current that can be decided, or in the short circuit MVA.

\section{II.2 Differential Relay}

The differential relay is one of the primary safety relays of the electric power system that works instantly without coordinating the surrounding relays so that working time can be made as quickly as possible [10].

Differential relay type is consists of a current differential relay and percentage differential relay.

1. Current differential relay

Differential current relays use quantities of incoming and outgoing currents from equipment that is secured for comparison in differential circuits. Every current difference is used to move the relay. Thus the currents of each phase are compared

2. Percentage differential relay

It has been described how the differential current relay works, so for the differential percentage relay has almost the same working characteristics as the differential current relay, it is just a differential circuit through a restraining coil. The differential current required to perform a relay has a varying magnitude; in other words, it is possible to have a relay setting. The differential current flowing into the relay is proportional to $\left(I_{1}-I_{2}\right)$, and the current flowing in the restrain coil is proportional to $\left(\mathrm{I}_{1}+\right.$ $\left.\mathrm{I}_{2}\right) / 2$ because the working coil is connected in the middle of the restraining coil.

The differential relay security area is limited by the current transformer pair where the differential relay is mounted so that the differential relay cannot be used as backup security for the next area. Differential relay protection works on the principle of the current balance. This principle is based on Kirchhoff's law, which is to compare the amount of incoming current to the primary (Ip) equals the amount of current coming out of the secondary (Is).

$$
I_{\text {differential }}=I_{d}=I_{p}+I_{S}
$$

where,

$$
\begin{aligned}
& \mathrm{I}_{\mathrm{d}}=\operatorname{Differential} \text { Current }(\mathrm{A}) \\
& \mathrm{I}_{\mathrm{p}}=\operatorname{Inrush} \text { Current }(\mathrm{A}) \\
& \mathrm{I}_{\mathrm{s}}=\operatorname{Outflow} \text { Current }(\mathrm{A})
\end{aligned}
$$

Figure 4 shows the differential relay under normal current state, where Ip and Is are equal and opposite direction, $\mathrm{I}_{\mathrm{d}}=\mathrm{I}_{\mathrm{p}}+\mathrm{I}_{\mathrm{s}}=0$ amperes, $\mathrm{I}_{\mathrm{dif}}=\mathrm{I}_{\mathrm{p}}+$ $I_{s}=0$ amperes. Then there is no voltage across the relay coil and no current flows in the relay, so the differential relay does not work properly. 


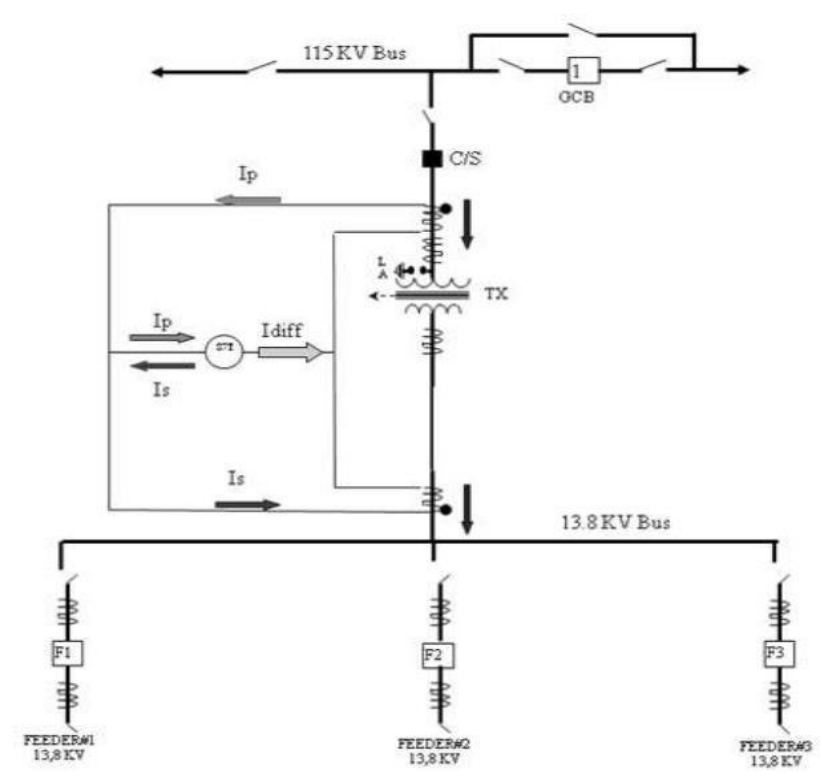

Fig. 4. Differential in normal condition

1. Interference outside the protected area

In interference outside (external) differential relay protection area (outside the two current transformers), differential relays will not work, because Ip and Is are equal and opposite direction $\left(\mathrm{I}_{\mathrm{d}}=\mathrm{I}_{\mathrm{p}}+\mathrm{I}_{\mathrm{s}}=0\right.$ ampere, $\mathrm{I}_{\text {dif }}=\mathrm{I}_{\mathrm{p}}+\mathrm{I}_{\mathrm{s}}=0$ Ampere $)$, as shown in Figure 5.

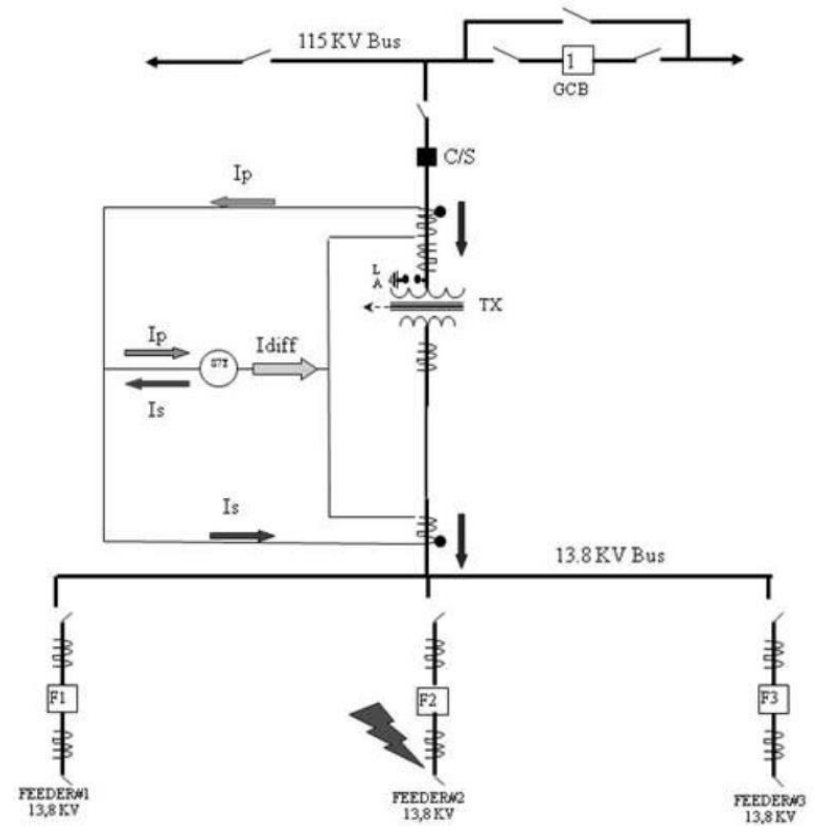

Fig. 5. Differential in external fault condition

2. Disturbances in protected areas

For interference in (internal) differential relay protection areas (between the two current transformers), Ip and Is unidirectional. $\mathrm{I}_{\mathrm{d}}=\mathrm{I}_{\mathrm{p}}+\mathrm{I}_{\mathrm{s}}>$ 0 ampere, $I_{\text {dif }}=I_{p}+I_{s}>0$ ampere. Because the current will go to the point of interference, the differential relay will work, as shown in Figure 6.

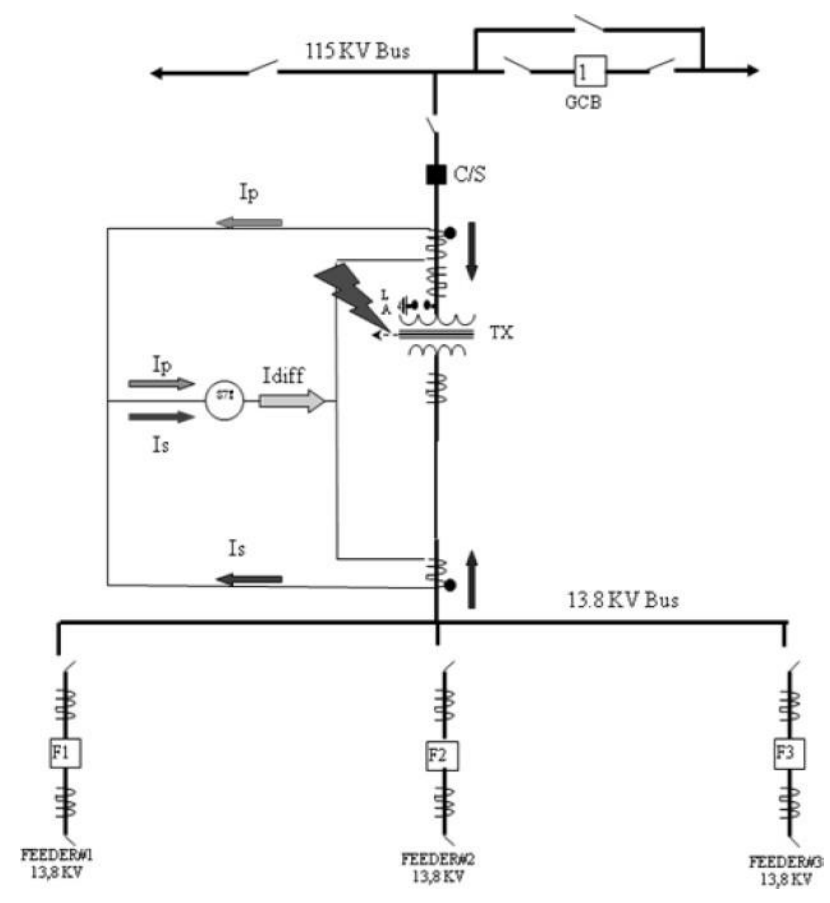

Fig. 6. Differential in internal fault condition

Differential characteristics are made in line with unbalances current $(I \mu)$, to avoid work errors. Work error caused by $\mathrm{CT}$ ratio mismatch, phase shift due to the winding of the connected power transformer (Y) - ( $\Delta$ ).

Changes in voltage tap (changes in the position of the tap changer) on the power transformer by the on-load tap changer (OLTC), which causes CT mismatch, also changes. CT accuracy errors, differences in CT errors in saturated regions (Saturation CT), and Inrush current when the transformer energizes raises transient unbalances current $\left(\mathrm{I}_{\mu}\right)$. Area of $\mathrm{I} \mu$. This coil is called the Restraining Coil, while the coil that works on the relay is called the Operating Coil. Differential current is obtained by adding up the secondary current component of the winding $1\left(\left|\mathrm{I}_{1}\right|\right)$ and winding $2\left(\left|\mathbf{I}_{2}\right|\right)$ in the perfection vector. If the currents are opposite in the sense that one goes to the relay and the other leaves the relay, they will reduce each other and vice versa if the direct current means both of them to go to or leave the relay, then they will add together.

The retrain current is obtained from the maximum current component of the per phase secondary current at winding $1\left(\left|\mathrm{I}_{1}\right|\right)$, and winding 2 $\left(\left|\mathrm{I}_{2}\right|\right)$ Slope is obtained by dividing between the differential current components and the holding current. Slope 1 will determine the differential current and the holding current during normal 
conditions and ensure the sensitivity of the relay in the case of internal interference with a small fault current. While Slope 2 is useful so that the relay does not work by external interference that has a considerable current so that one CT has saturation (set with a slope of more than 50\%).

\section{Methodology}

This research methodology includes a literature study, field surveys, expert discussions, and simulations using ETAP software. A literature study can be done by looking for references related to the protection system theory on the main transformer and the theory of differential relays, which are used as the main protection relay in the main transformer at Unit 4 Geothermal Power Plant in Kamojang area.

The field survey method was carried out by conducting a visit to PT Pertamina Geothermal Energy in Kamojang area, followed by a discussion with the field supervisor.

Discussion activities with experts and also to employees, supervisors, and electrical maintenance managers at PT. Pertamina Geothermal Energy, regarding the problem to be analyzed. The dialysis issue is related to the operation of differential relays in handling power transformer interference. The authors discuss the differential relay settings so far in the field; then the authors carry out simulations using ETAP software for validation.

The authors simulated interference with power transformers that experienced internal and external disturbances; then differential relays did their job of deciding interference. The simulation is done using ETAP 12.6 software.

\section{Results and Discussion}

The following are transformer data used by unit 4 of the Geothermal Power Plant in the PT Pertamina Geothermal Energy Kamojang area. Specification of power transformer under study was shown in Table 1 . As can be seen in the Table, the capacity of the power transformer is $80 \mathrm{MVA}$.

TABLE I

SPECIFICATION OF POWER TRANSFormer Under Study

\begin{tabular}{lc}
\hline $\begin{array}{c}\text { Parameter of power } \\
\text { transformer }\end{array}$ & Quantities and Units \\
\hline Power capacity & $80 \mathrm{MVA}$ \\
Primary voltage & $13.8 \mathrm{kV}$ \\
Secondary voltage & $150 \mathrm{kV}$ \\
Power frequency & $50 \mathrm{~Hz}$ \\
Impedance & $13.8 \%$ \\
\hline \hline
\end{tabular}

The allowable current setting limit on the low voltage side power transformer is $0.3 \mathrm{~A}$ according to the mathematical and actual calculations in PGE; if it exceeds the allowed setting current value, the differential relay will detect interference and instruct the PMT to trip the network.

TABLE II

SETting of ACtUAL DifFERENTIAL RELAy

\begin{tabular}{lc}
\hline \hline Setting of differential relay & Range \\
\hline Electrical current setting & $0.3 \mathrm{~A}$ \\
Percentage of slope \#1 & $40 \%$ \\
Percentage of slope \#1 & $80 \%$ \\
\hline \multicolumn{2}{c}{$\quad$ TABLE III } \\
\multicolumn{2}{c}{$\quad$ RELAY } \\
\multicolumn{2}{c}{ SETTING USING MANUAL CALCULATION OF DIFFERENTIAL } \\
\hline Setting of differential relay & Range \\
\hline Electrical current setting & $0.3 \mathrm{~A}$ \\
Percentage of slope \#1 & $8.5 \%$ \\
Percentage of slope \#1 & $17 \%$ \\
\hline \hline
\end{tabular}

Table 2 shows the setting of actual differential relay while setting using manual calculation of differential relay was shown in Table 3 .

Percent slope 1 and 2, there is a difference between the actual setting data and manual calculation data with an error of each slope of $370 \%$. This setting was done by PT Pertamina geothermal energy with the aim that the differential relay is not too sensitive to the current passing through the protection zone so that the setting of each slope is changed to $40 \%$ for slope 1 and $80 \%$ for slope 2 .

When given a short circuit simulation outside the differential relay protection zone, the current setting will be equal to the operating current of 0.926 on bus 4. However, the circuit breaker still works because the circuit breaker works in coordination with overcurrent relays and overvoltage relays to line the network.

Figure 7 shows the simulation of short-circuit fault in external fault condition using ETAP software while simulation of short-circuit fault in internal fault condition using ETAP software was shown in Figure 8. When given a short circuit simulation in the differential relay protection zone, the setting current will be different from the operating current, which is the setting current 9.15 A while the operating current will be 17.17 A. Then, the relay will instruct $\mathrm{CB}$ to write the network. 


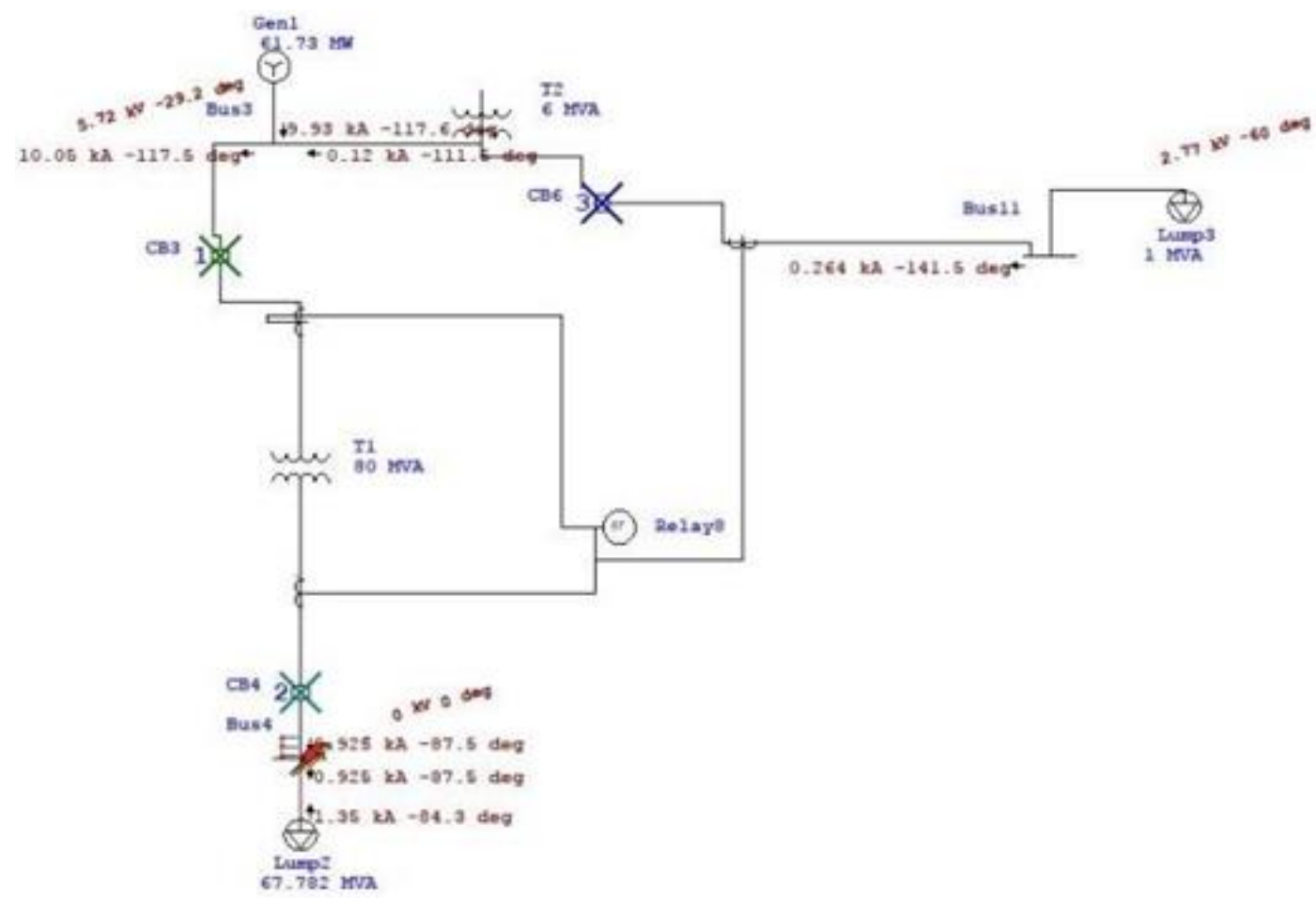

Fig. 7. Simulation of short-circuit fault in external fault condition using ETAP software

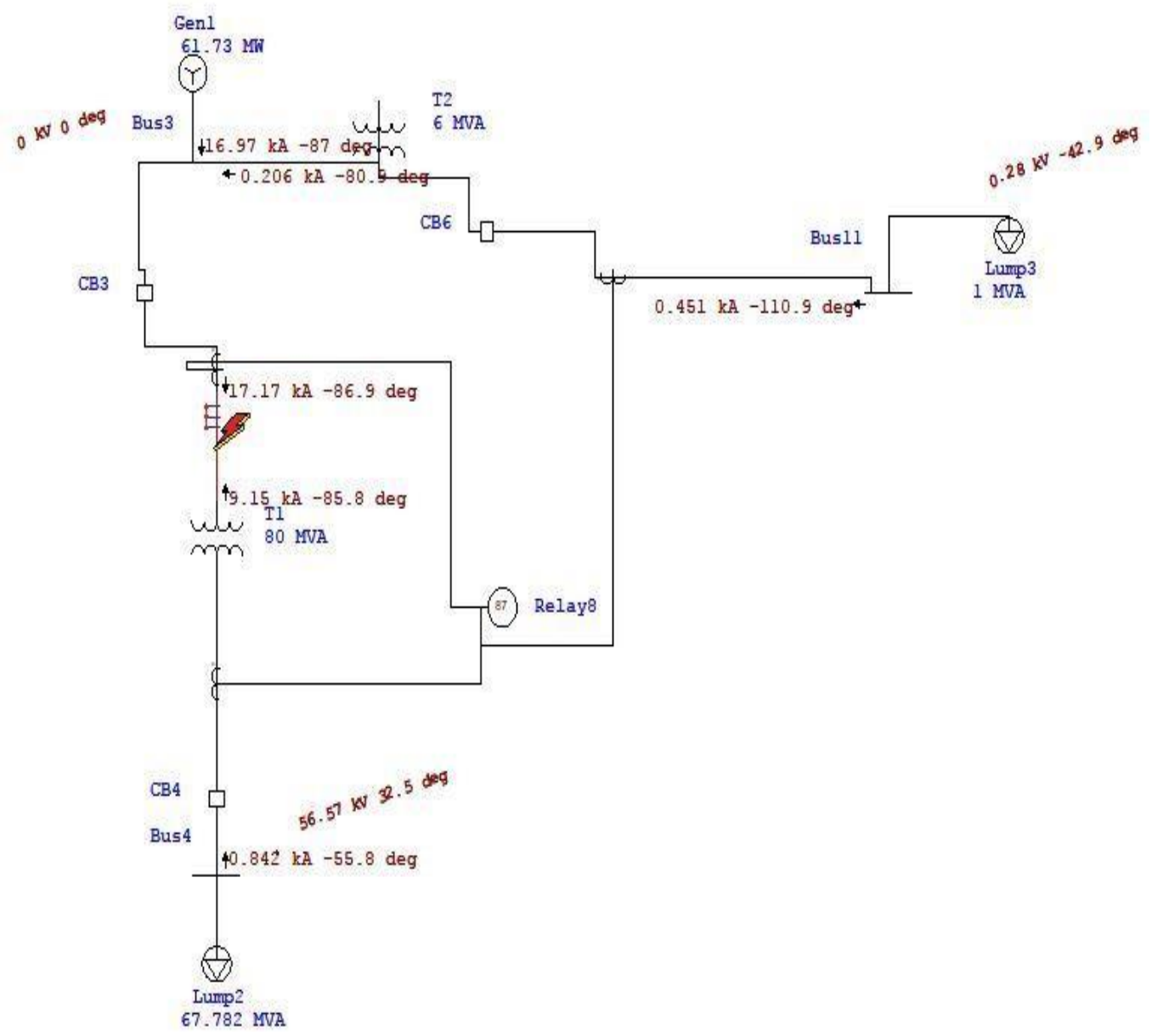

Fig. 8. Simulation of short-circuit fault in internal fault condition using ETAP software 


\section{Conclusion}

Based on the results of the study, it can be concluded as follows. The allowable current setting limit on the low voltage side power transformer is $0.3 \mathrm{~A}$ according to the mathematical and actual calculations in PGE; if it exceeds the allowed setting current value, the differential relay will detect interference and instruct the PMT to trip the network. Percent slope 1 and 2, there is a difference between the actual setting data and manual calculation data with an error of each slope of 370\%. This setting was done by PT Pertamina Geothermal Energy with the aim that the differential relay is not too sensitive to the current that passes through the protection zone so that the setting of each slope is changed to $40 \%$ for slope 1 and $80 \%$ for slope 2 . The short circuit which is done outside the differential relay current setting protection zone will be worth the same as the operating current is 0.926 on bus 4. But in the simulation that has been done that the circuit breaker still works because the circuit breaker works in coordination with overcurrent relays and overvoltage relays to write the network. While the short circuit in the differential relay protection zone, the setting current will be different from the operating current, which is the setting current 9.15 A. In contrast, the operating current will be worth 17.17 A. Then, the relay will instruct $\mathrm{CB}$ to write the network.

\section{References}

[1] J. G. Adrichak, J. Cardenas, "Bus differential protection", 22nd WPRC Conference, pp. 1-11, October 1995.

[2] Syahputra, R. (2010). Fault Distance Estimation of Two-Terminal Transmission Lines. Proceedings of International Seminar on Applied Technology, Science, and Arts (2nd APTECS), Surabaya, 21- 22 Dec. 2010, pp. 419-423.

[3] W. Guan, K. J. R. Liu, "Performance analysis of two-way relaying with non-coherent differential modulation", IEEE Trans. Wireless Commun., vol. 10, no. 6, pp. 2004-2014, June 2011.

[4] W. Rebizant, T. Hayder, L. Schiel, "Prediction of CT saturation period for differential relay adaptation purposes", International Conference on Advanced Power System Automation and Protection, pp. 1-6, 2004.

[5] GEK-45307K-Transformer Differential Relays with Percentage and Harmonic Restraint Types STD15C and STD16C GE Protection \& Control, Malvern, PA, pp. 12-13.
[6] B. Kasztenny, A. Kulidjian, "Differential protective relay for electrical buses with improved immunity to saturation of current transformers", April 2000.

[7] M. R. Avendi, Ha. H Nguyen, "Differential dual-hop relaying over time varying Rayleigh fading channel", IEEE Conference, June 2013.

[8] J. O. Aibangbee, Bells, Ota, "Power Transformer Inrush Current Detection \& Harmonic Sharing In Differential Relay Protection", International Journal of Engineering Trends and Technology (IJETT), vol. 33, March 2016.

[9] Byung, "Saturation Detection-Based Blocking Scheme for Transformer Differential Protection", journal paper Energies, vol. 7, pp. 4571-4587, 2014.

[10] J. O. Aibangbee, S. O. Onohaebi, "Power Transformer Differential Relay Inrush Restraint Setting Applications", IOSR Journal of Electrical and Electronics Engineering (IOSR-JEEE), vol. 11, no. 1, pp. 68-75, Jan. 2016.

[11]I. Kim, P. Liu, S. Gazor, D. Kim, "Noncoherent amplify-and-forward cooperative networks: Robust detection and performance analysis", IEEE Trans. Commun., vol. 61, no. 9, pp. 3644-3659, Sept. 2013.

\section{Authors' information}

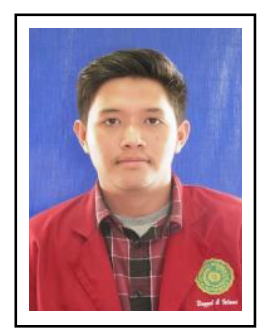

Gady Altama received B.Sc. degree from Department of Electrical Engineering, Universitas Muhammadiyah Muhammadiyah Yogyakarta, Yogyakarta, Indonesia, in 2018.

His research interests are in operation of power distribution system and power system protection.

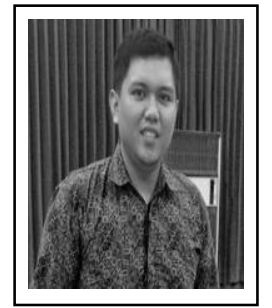

Muhamad Yusvin Mustar Received Diploma degree Electrical Engineer from Universitas Haluoleo, Kendari in 2009, B.Sc. degree from from Department of Electrical Engineering Universitas Muhammadiyah Yogyakarta in 2011, M.Eng. degree from Department of Electrical Engineering and Informatics Technology, Universitas Gadjah Mada, Yogyakarta, Indonesia in 2014.

Muhamad Yusvin Mustar, M.Eng. is a Lecturer in Department of Electrical Engineering, Faculty of Engineering, Universitas Muhammadiyah Yogyakarta, Indonesia. His research interests are in human-robot interaction, human-machine interaction, robotics, electrical and electronics engineering.

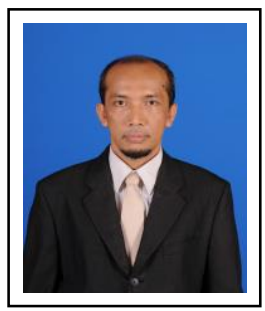

Ramadoni Syahputra received B.Sc. degree from Institut Teknologi Medan in 1998, M.Eng. degree from Department of Electrical Engineering, Universitas Gadjah Mada, Yogyakarta, Indonesia in 2002, and Ph.D degree at the Department of Electrical Engineering, Faculty of Industrial Technology, Institut Teknologi Sepuluh Nopember, Surabaya, Indonesia in 2015. 
Dr. Ramadoni Syahputra is a Lecturer in Department of Electrical Engineering, Faculty of Engineering, Universitas Muhammadiyah Yogyakarta, Indonesia. His research interests are in computational of power system, artificial intelligence in power system, power system control, the application of fuzzy logic in power system, optimization, distributed energy resources, and renewable energy.

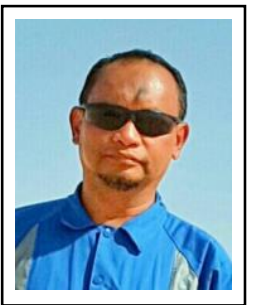

Teguh Iman Prasetyo hold a bachelor degree in 2000 from Electrical Engineering Department, Universitas Muhammadiyah Yogyakarta, Indonesia. Mr. Teguh Iman Prasetyo is currently a professional in Production on the Job Trainer and Competence Assessor, Petroleum Development Oman, Muscat, Sultanate of Oman. His main research interest is in control system and distributed control system. 